\title{
Traumatic Brain Injury: Prognostic Value of Various Coma Scales, CT Scores \& Their Comparison Based on Clinical Outcome
}

\author{
Ashrit Reddy Cheruku' ${ }^{1}$, Suryanarayan Reddy $\mathbf{V}^{2}$ \\ ${ }^{1}$ Assistant Professor, ${ }^{2}$ Professor, \\ Department of General Surgery, Chalmeda Anand Rao Institute of Medical Sciences, Karimnagar.
}

Corresponding Author: Suryanarayan Reddy V

\begin{abstract}
Background: Traumatic brain injury (TBI) is common, carries a high morbidity and mortality and has no specific treatment. The Glasgow coma scale (GCS) is considered the gold standard for assessment of unconsciousness in patients with traumatic brain injury against which other scale are compared to overcome the disadvantages of GCS.
\end{abstract}

Materials \& Methods: This is Prospective Observational comparative study was conducted in total 128 who admitted with traumatic brain injury (TBI) in Department of General Surgery, Chalmeda Anand Rao Institute of Medical Sciences, Karimnagar during the period from November 2016 to November 2018.

Results: A total of 128 (112 males) patients were included in the study. Among SMS, 0 is highly sensitive $(72.22 \%), 2$ is highly specific $(80.43 \%)$. In GCS score $\leq 8$ was highly sensitive $(97.22 \%)$ \& GCS score 9 - 12 was highly specific $(82.61 \%)$. In this study Marshall CT score of 4 - 6 (group II) has mortality $43.55 \%$ \& CT score 1 - 3 (group I) was $13.64 \%$. Where as in Rotterdam CT score was significant mortality with score 4 - 6 (group II) was $56.25 \%$ \& CT score of 1 - 3 (group I) was $24.11 \%$. In FOUR score with GCS, on 1 day with FOUR score 13 - 16 (group IV) has 5.56\%, day 3, 13 16 (group IV) has $3.45 \%$, day 7, 13 - 16 (group IV) has $3.13 \%$ \& day 21,13 - 16 (group IV) only $3.45 \%$ has mortality rate.

Conclusion: if SMS is high there is more chance of survival, this helps in patients immediate segregation of patients in casualty. Also conclude that FOUR score has a high degree of internal consistency \& is an accurate predictor of Mortality and neurologic outcome in TBI patients.

Keyword: Simplified Motor Score, Glasgow Coma Scale, Marshall CT, Rotterdam CT, FOUR scale.

\section{INTRODUCTION}

Traumatic brain injury (TBI) is a major cause of death and disability worldwide. To assess the level of consciousness after TBI, Teasdale and Jennett in 1974 described a coma scale known as the Glasgow Coma Scale (GCS) (1). Patients can be assessed clinically with Simplified motor score (SMS) which has three components derived from the motor components of GCS (2) The Glasgow Outcome Scale (GOS) is a functionally based assessment tool for use with head injured patients, which was devised primarily for use in epidemiological and early management research in order to provide reliable standardised categories of outcome. Its widespread acceptance would facilitate inter centre comparisons and when used in conjunction with the GCS be helpful for predicting outcome after severe head injury ${ }^{(3)}$.

Besides clinical evaluation by GCS scoring, intracranial lesions in these patients can be detected early by Computed tomography (CT) which remains the primary investigation of choice in most of the cases of TBI in places where the services are available. Early detection of the 
lesions in TBI by using CT imaging can improve the context of clinical management with a better outcome in these patients. Despite high advantages of CT imaging this procedure may not be available in all the settings and is also associated with certain contraindications. In recent years CT scanning has become a routine investigation and been ordered in all the cases of head injury from the emergency department. Most of the literature reports that CT scans are necessary immediately after head injury and also during follow up also after treatment interventions. Hence developing possible alternative modalities to avoid unnecessary CT scans and hazards of radiation is necessary in cases of TBI. ${ }^{(4)}$

However, GCS differentiates poorly between patients with low GCS, and also in intubated patients. Also, there are certain drawbacks of the GCS system such as skewness towards motor score, an inability to assess verbal score in intubated and aphasic patients, and a lack of brainstem reflexes.

In order to overcome the disadvantages of GCS, Widjicks et al. published the Full Outline Of Unresponsiveness (FOUR) score in $2005^{(5)}$. It provides additional information about brainstem function and respiratory drive. The FOUR score is useful even in intubated patients as verbal response is not a component of FOUR score. The four components of FOUR score are: eye tracking, motor response, brainstem function, and respiratory drive. Each category is given $0-4$ points, 0 being the worst and 4 being the best. The FOUR score has been found to be superior in the assessment of comatose patients ${ }^{(6)}$. The purpose of this study was to compare of SMS, GCS, GOS, CT \& FOUR score in admitted patients in the department of neurosurgery with TBI.

\section{MATERIALS \& METHODS}

This is Prospective Observational comparative study. An approval from Institutional Ethical committee was obtained from the institute. The study population consists of 128 patients admitted with Traumatic brain injury (TBI) in Department of General Surgery, Chalmeda Anand Rao Institute of Medical Sciences, Karimnagar during the period from November 2016 to November 2018. SMS and GCS of each patient were assessed clinically by examiner, paramedic and neurosurgeon. The average of scores assessed by these three people was compared with GOS on 21st day / on the day of death and early discharge.

SMS has only three components but GCS has 15 components divided into three group (Group I was GCS $\leq 8$, Group II was 9 - 12 \& Group III was 13) and also correlation comparison of these two scores with GOS on 21st day / on the day of death and early discharge.

After doing CT head according to protocols in head injury patients, Marshall and Rotterdam CT score evaluation was done by examiner and neurosurgeon. The average of these scores assessed by these two people was compared with GOS on 21st day / on the day of death and early discharge.

FOUR score evaluation done in NSICU on day 1 , day 3 , day 7 , and day 21 / on the day of death or earlier discharge by examiner, paramedic and neurosurgeon. The average of these scores compare with GOS on 21 st day / on the day of death and early discharge.

Statistical Analysis: For statistical analysis, mean \pm standard deviation was determined to describe continuous variables and frequency (percentage) was used to describe categorical variables. Data were analysed using IBM SPSS Statistics for Mac's, Version 23.0.

\section{RESULTS}

The present study was conducted for a period of two years in Department of Surgery and included 128 patients with history of traumatic brain injury. A total of 128 patients were included in the study. Out of these $112(87.5 \%)$ patients were male \& 
most common road traffic accident occurred in 21 to 30 years age group being 36 (28.13\%) patients. The Simplified motor score component was $0,1 \& 2$ in 67 $(52.3 \%), \quad 43 \quad(33.6 \%) \quad \& \quad 18 \quad(14.1 \%)$ respectively. The Glasgow Coma score grouping was Group I, II \& III in 90
$(70.3 \%), \quad 17 \quad(13.3 \%) \quad \& \quad 21 \quad(16.4 \%)$ respectively. The Marshall CT scan grouping was group I \& II in $66(51.6 \%) \&$ $62(48.4 \%)$. Similarly the Rotterdam CT scan grouping was group I \& II in 112 $(87.5 \%) \& 16(12.5 \%)$. (table 1)

Table No. 1: Comparison of SMS, GCS, Marshall CT, Rotterdam CT, FOUR score on day 1 of admission with GOS on 21st day / on the day of death and early discharge.

\begin{tabular}{|c|c|c|c|c|c|c|c|c|}
\hline \multirow{2}{*}{\multicolumn{2}{|c|}{ Scale }} & \multicolumn{5}{|c|}{ GOS } & \multirow[t]{2}{*}{ Total } & \multirow[t]{2}{*}{ P value } \\
\hline & & $\mathbf{1}$ & 2 & 3 & 4 & 5 & & \\
\hline \multirow[t]{3}{*}{ SMS } & 0 & 26 & 21 & 12 & 1 & 7 & 67 & \multirow[t]{3}{*}{0.0001} \\
\hline & 1 & 10 & 7 & 6 & 3 & 17 & 43 & \\
\hline & 2 & 0 & 0 & 0 & 7 & 11 & 18 & \\
\hline \multirow[t]{3}{*}{ GCS } & $\leq 8($ Group $\mathrm{I})$ & 35 & 28 & 15 & 4 & 8 & 90 & \multirow[t]{3}{*}{0.0001} \\
\hline & $9-12$ (Group II) & 1 & 0 & 3 & 2 & 11 & 17 & \\
\hline & 13 (Group III) & 0 & 0 & 0 & 5 & 16 & 21 & \\
\hline \multirow[t]{2}{*}{ Marshall CT } & $1-3$ (Group I) & 9 & 17 & 8 & 7 & 25 & 66 & \multirow[t]{2}{*}{0.0014} \\
\hline & 4 -6 (Group II) & 27 & 11 & 10 & 4 & 10 & 62 & \\
\hline \multirow[t]{2}{*}{ Rotterdam CT } & 1 - 3 (Group I) & 27 & 24 & 15 & 11 & 35 & 112 & \multirow[t]{2}{*}{0.016} \\
\hline & 4 -6 (Group II) & 9 & 4 & 3 & 0 & 0 & 16 & \\
\hline \multicolumn{2}{|l|}{ Total } & 36 & 28 & 18 & 11 & 35 & 128 & \\
\hline
\end{tabular}

In the below table no. 2 shows that FOUR score on day 1 with FOUR score 0-4 has deaths 3 out of $5(60 \%)$ and 5-8 score has 23 deaths out of 46 patients $(50 \%)$. In day 3 also FOUR score has significant mortality rate in score $<8$ (20 out of 45 patients). If score 13-16 only 1 patient has death out of 29 patients $(3.45 \%)$ and 21patients out of 29 discharged with minimal disability (GOS 5). On day 7 FOUR score between 13-16, 23 out of 32 patients $(71.88 \%)$ can expect discharge with minor deficit (GOS 5). On day 21st only 1 patients has unresponsiveness (GOS2) on score $<4$ and 18 patients out of $29(62.07 \%)$ discharged with minor disability (GOS 5) if score between 13-16.

\begin{tabular}{|c|c|c|c|c|c|c|c|c|}
\hline \multirow{2}{*}{\multicolumn{2}{|c|}{ FOUR Score }} & \multicolumn{5}{|c|}{ GOS } & \multirow[t]{2}{*}{ Total } & \multirow[t]{2}{*}{$P$ value } \\
\hline & & 1 & 2 & 3 & 4 & 5 & & \\
\hline \multirow[t]{4}{*}{ Day 1} & 0 - 4 (Group I) & 3 & 1 & 1 & 0 & 0 & 5 & \multirow[t]{4}{*}{0.0001} \\
\hline & 5 - 8 (Group II) & 23 & 13 & 10 & 0 & 0 & 46 & \\
\hline & 9 - 12 (Group III) & 9 & 14 & 6 & 9 & 21 & 59 & \\
\hline & $13-16$ (Group IV) & 1 & 0 & 1 & 2 & 14 & 18 & \\
\hline \multirow[t]{4}{*}{ Day 3} & $0-4$ (Group I) & 1 & 0 & 1 & 0 & 0 & 2 & \multirow[t]{4}{*}{0.0001} \\
\hline & 5 - 8 (Group II) & 19 & 16 & 6 & 2 & 0 & 43 & \\
\hline & $9-12$ (Group III) & 7 & 10 & 11 & 4 & 12 & 44 & \\
\hline & $13-16$ (Group IV) & 1 & 2 & 0 & 5 & 21 & 29 & \\
\hline \multirow[t]{4}{*}{ Day 7} & 0 - 4 (Group I) & 0 & 0 & 0 & 0 & 0 & 0 & \multirow[t]{4}{*}{0.0001} \\
\hline & 5 - 8 (Group II) & 18 & 14 & 6 & 1 & 0 & 39 & \\
\hline & $9-12$ (Group III) & 3 & 12 & 11 & 1 & 5 & 32 & \\
\hline & $13-16$ (Group IV) & 1 & 2 & 1 & 5 & 23 & 32 & \\
\hline \multirow[t]{4}{*}{ Day 21} & 0 - 4 (Group I) & 0 & 1 & 0 & 0 & 0 & 1 & \multirow[t]{4}{*}{0.0001} \\
\hline & 5 - 8 (Group II) & 12 & 14 & 10 & 1 & 0 & 37 & \\
\hline & 9 - 12 (Group III) & 2 & 10 & 9 & 1 & 2 & 24 & \\
\hline & $13-16$ (Group IV) & 1 & 0 & 5 & 5 & 18 & 29 & \\
\hline Total & & 36 & 28 & 18 & 11 & 35 & 128 & \\
\hline
\end{tabular}

In the below table no. 3 shows that SMS has more sensitive $(72.22 \%)$ with score 0 and more specificity $(80.43 \%)$ with score 2. CGS has more sensitive $(97.22 \%)$ with score $\leq 8$ (Group I) and more specificity $(82.61 \%)$ with score $9-12$ (Group
II). If score is $1-3$, Rotterdam is more sensitive than Marshall (75\%>25\%). If CT score is $>3$, Marshall is more sensitive than Rotterdam $(75 \%>25 \%)$. Rotterdam score is more specific than Marshall CT score $(92.39 \%>61.96 \%)$, if score $>3)$. Rotterdam 
CT score is more accurate and has high relative risk ratio than Marshall CT score.

Table No. 3 : Diagnostic analysis of SMS, GCS, Marshall CT, Rotterdam CT score with GOS on 21st day/ on the day of death and early discharge

\begin{tabular}{|l|l|l|l|l|l|l|}
\hline Scale & Sensitivity & Specificity & Accuracy & Odds Ratio & Relative Risk \\
\hline \multirow{3}{*}{ SMS } & 0 & $72.22 \%$ & $55.43 \%$ & $60.16 \%$ & $3.23(1.4-7.47)$ & $2.36(1.24-4.49)$ \\
\cline { 2 - 7 } & 1 & $27.78 \%$ & $64.13 \%$ & $53.91 \%$ & $0.68(0.29-1.6)$ & $0.76(0.40-1.42)$ \\
\cline { 2 - 7 } & 2 & 0 & $80.43 \%$ & $57.81 \%$ & $0.05(0.003-0.94)$ & $0.08(0.005-1.25)$ \\
\hline \multirow{3}{*}{ GCS } & $\leq 8$ (Group I) & $97.22 \%$ & $40.22 \%$ & $56.25 \%$ & $23.54(3.09-179.45)$ & $0.16(0.02-1.16)$ \\
\cline { 2 - 7 } & $9-12$ (Group II) & $2.78 \%$ & $82.61 \%$ & $60.16 \%$ & $0.13(0.017-1.06)$ & $0.16(0.02-1.16)$ \\
\cline { 2 - 7 } & 13 (Group III) & 0 & $77.1 \%$ & $55.47 \%$ & $0.045(0.0027-0.77)$ & $0.05(0.003-0.94)$ \\
\hline \multirow{2}{*}{ Marshall CT } & $1-3$ (Group I) & $25 \%$ & $38.04 \%$ & $34.38 \%$ & $0.20(0.08-0.48)$ & $0.40(0.22-0.72)$ \\
\cline { 2 - 7 } & $4-6$ (Group II) & $75 \%$ & $61.96 \%$ & $65.62 \%$ & $4.88(2.06-11.59)$ & $1.97(1.43-2.71)$ \\
\hline \multirow{2}{*}{ Rotterdam CT } & $1-3$ (Group I) & $75 \%$ & $7.61 \%$ & $26.56 \%$ & $0.24(0.08-0.72)$ & $0.81(0.66-0.99)$ \\
\cline { 2 - 7 } & $4-6$ (Group II) & $25 \%$ & $92.39 \%$ & $73.44 \%$ & $4.04(1.37-11.9)$ & $3.28(1.32-8.16)$ \\
\hline
\end{tabular}

\section{DISCUSSION}

Traumatic brain injury is one of the major public problems which have gained wide importance. Literature and reports of various studies state that these injuries account for $3 \%$ to $10 \%$ of deaths and these deaths occur mostly in young adults which are of real concern. In India the figures of mortality, morbidity and disability in cases of TBI due to road traffic agents are a real threat to the country. Higher incidence is observed mostly in young adults.

In the present study, a total 128 patients were included and male accounting of $87.5 \%$ which was higher to most of the reports globally.

In this study compared SMS and GCS on admission to GOS on 21st day / on the day of death and early discharge to know which score is better for assessment of traumatic brain injury patients.

In this study, if SMS score is 2 there was no mortality and if score is 0 only $38.81 \%$ of patients have mortality (table 1 ). Among SMS, 0 is highly sensitive (72.22\%), 2 is highly specific $(80.43 \%)$.

In GCS score $\leq 8$, indicates more chance of mortality (38.89\%), GCS score 9 - 12 only $1(5.88 \%)$ patients was died \& GCS score 13 has no mortality (table 1). In GCS score $\leq 8$ was highly sensitive $(97.22 \%)$ \& GCS score 9-12 was highly specific $(82.61 \%)$, that means if SMS is high there is more chance of survival, this helps in patients immediate segregation of patients in casualty.

Similarly Gill et al ${ }^{(7)}$ proposed a further simplification of the motor component to a 3 point SMS and showed it to have nearly equivalent discriminatory ability and excellent inter observer reliability compared with the full GCS.

In this study Marshall CT score of 4 - 6 (group II) has mortality $43.55 \%$ \& CT score 1 - 3 (group I) was $13.64 \%$. Where as in Rotterdam CT score was significant mortality with score 4-6 (group II) was $56.25 \%$ \& CT score of $1-3$ (group I) was $24.11 \%$. In these two scores, Rotterdam CT score is better to predict of mortality (table 1). In this study was found that Rotterdam CT score is more sensitive than Marshall CT score in group I \& Marshall CT score is more sensitive than Rotterdam CT score in group II.

In the study done by Munakomi et al (8) to shows the significant importance of Marshall score in predicting mortality in patients with TBI. The mortality in patients with Marshall score $1 \& 2$ is $0 \%$, for score 3 is $40 \%$, for score 4 is $0 \%$, for score 5 is $18.79 \%$ and for score 6 is $95.66 \%$. This clearly proves the value of evacuation of mass lesion in patients with TBI in reducing the mortality compared to the patients with compressed cisterns, midline shift and non evacuated $>25 \mathrm{ml}$ blood. Mortality in their patients with Rotterdam score $1 \& 2$ is $0 \%$, for score 3 is $6 \%$, for score 4 is $35 \%$, for score 5 is $53.65 \%$ \& for score 6 is $58.33 \%$. This proves that higher Rotterdam score in patients with TBI has added risk of mortality.

In this study was also compare with FOUR score with GCS, on 1 day with FOUR score 0-4 (group I) has $60 \%$ 
mortality, 5 - 8 (group II) has 50\%, 9 - 12 (group III) has $15.25 \%$ \& $13-16$ (group IV) has $5.56 \%$ mortality. In day 3 , if score was 13 - 16 (group IV) only $3.45 \%$ has mortality rate. In day 7 , if score was 13 - 16 (group IV) only $3.13 \%$ has mortality rate \& day 21 , if score 13 - 16 (group IV) only $3.45 \%$ has mortality rate (table 2).

Similar Sadaka et al ${ }^{(9)}$ was done prospective study population may not have included enough severely injured patents, as the in hospital mortality was $7.8 \%$. Also a smaller proportion of patients had GCS score <9. Their study also reflects the difficulty of carrying such a study on TBI patients, since they had to exclude 14 patients because they were heavily sedated in this early period of head injury and thus they were unable to obtain FOUR score or GCS accurately.

\section{CONCLUSION}

In this study it was concluded that SMS score was better for assessment of traumatic brain injury \& will help in triaging head injury patients in mass casualty. Also Rotterdam CT score is better reliability than Marshall CT score on GCS score. Also conclude that FOUR score has a high degree of internal consistency \& is an accurate predictor of Mortality and neurologic outcome in TBI patients.

\section{Acknowledgement: None}

\section{Conflict of Interest: None}

\section{Source of Funding: None}

Ethical Approval: Approved by Institutional Ethical Committee

\section{REFERENCES}

1. Teasdale G, Jennett B (1974) Assessment of coma and impaired consciousness. A practical scale. Lancet 2:81-84.

2. Singh B., Murad MH., Prokop LJ., Erwin PJ., Wanfg Z., Mommer SK., et. al. Meta analysis of Glasgow coma scale and simplified motor score in predicting traumatic brain injury outcomes. Brain Inj. 2013;27(3):293-300. doi: 10.3109/ 02699052.2012 .743182 .

3. Anderson SI., Housley AM., Jones PA., Slattery J., \& Miller JD. Glasgow Outcome scale: An inter-rater reliability study. Brain Inj. Jul-Aug 1993;7(4):309-17. doi: 10.3109/02699059309034957

4. Schackford SR, Wald SL, Ross SE, et al. The clinical utility of computed tomographic scanning and neurologic examination in the management of patients with minor head injuries. J Trauma 1992; 33 (6):385-394.

5. Wijdicks EF, Bamlet WR, Maramattom BV, Manno EM, McClelland RL (2005) Validation of a new coma scale: the FOUR score. Ann Neurol 58:585-593.

6. Stead LG, Wijdicks EF, Bhagra A, Kashyap R, Bellolio MF, Nash DL, Enduri S, Schears R, William B (2009) Validation of New Coma Scale, the FOUR score, in the Emergency Department. Neurocrit Care 10:50-54.

7. Gill M., Steele R., Windemuth R., et al. A comparison of five simplified scales to the out of hospital Glasgow Coma Scale for the prediction of traumatic brain injury outcomes. Acad Emerg Med. 2006; 13: 968 $-973$.

8. Munakomi S. A comparative study between Marshall and Rotterdam CT scores in predicting early deaths in patients with traumatic brain injury in a major tertiary care hospital in Nepal. Chinese $\mathrm{J}$ traumatic English ed. 2016; 19(1): 25 - 7.

9. Sadaka F., Patel D., Lakshamanan R. The FOUR score predicts outcome in patients after traumatic brain injury. Neurocrit Care. 2012; 16 (1): 95 - 101.

How to cite this article: Cheruku AR, Suryanarayan Reddy V. Traumatic brain injury: Prognostic value of various coma scales, CT scores \& their comparison based on clinical outcome. Gal Int J Health Sci Res. 2021; 6(3): 26-30. DOI: https://doi.org/10.52403/gijhsr. 20210705 